\title{
Team Visibility and City Travel: Evidence From the UEFA Champions' League Random Draw
}

\author{
Caprettini, Bruno
}

\begin{abstract}
Does hosting a sports team boost the visibility of a city among tourists? I test this proposition by looking at the effect of playing soccer's UEFA Champions' League on air travel. I compare routes across cities that had their teams randomly drawn into the same group in the first phase of the competition to routes across cities hosting teams randomly allocated to different groups. The average effect of being drawn into the same group is between $5 \%$ and $8 \%$ more arrivals for the 3 months following the group stage, a period which coincides with a break in the competition. The first appearance of a team in the competition has a larger impact on air travel, providing suggesting evidence of diminishing returns of exposure.
\end{abstract}

DOI: https://doi.org/10.1177/1527002520955208

Posted at the Zurich Open Repository and Archive, University of Zurich ZORA URL: https://doi.org/10.5167/uzh-190377

Journal Article

Accepted Version

Originally published at:

Caprettini, Bruno (2021). Team Visibility and City Travel: Evidence From the UEFA Champions' League Random Draw. Journal of Sports Economics, 22(1):85-114.

DOI: https://doi.org/10.1177/1527002520955208 
Accepted for publication at Journal of Sports Economics

https://journals.sagepub.com/doi/full/10.1177/1527002520955208gb 


\title{
Team Visibility and City Travel \\ Evidence from the UEFA Champions League Random Draw
}

\author{
By Bruno Caprettini * \\ Does hosting a sports team boost the visibility of a city among tourists? I test this \\ proposition by looking at the effect of playing soccer's UEFA Champions League \\ on air travel. I compare routes across cities that had their teams randomly drawn \\ into the same group in the first phase of the competition to routes across cities \\ hosting teams randomly allocated to different groups. The average effect of being \\ drawn into the same group is between 5 and 8 percent more arrivals for the three \\ months following the group stage, a period which coincides with a break in the \\ competition. The first appearance of a team in the competition has a larger \\ impact on air travel, providing suggesting evidence of diminishing returns of \\ exposure.
}

Keywords: team visibility; air travel; football; UEFA Champions League; natural experiment.

\footnotetext{
* Caprettini: University of Zurich, Schoenberggasse, 1, Zurich, Switzerland 8001 (e-mail: bruno.caprettini@gmail.com; tel: $+41(0) 446345569)$. Special thanks to Antonio Ciccone for his constant feedback and encouragement. Thanks also to two anonymous referees, the editor as well as Ciccio Amodio, Dennis Coates, Dmitry Dagaev, Helmut Dietl, Patricia Funk, Marc Goñi, Libertad Gonzalez, Ignacio Huerta, Brad Humphreys, Stephan Litschig, Tom Schmitz, Alessandro Tarozzi, Jag Tripathy and participants at the $2^{\text {nd }}$ International Academic Conference on Economics of Football and at the CRSA Sports, Data and Journalism Conference for very valuable suggestions. All errors are mine.
} 


\section{Introduction}

Professional teams are often taken to increase their home city's visibility among tourists. As teams get extensive media coverage, their home cities make the news, and this is thought to turn anonymous places into potential tourism destinations. Such potential benefits are often behind sports teams' demands for public subsidies. Yet, so far no analysis has shown that the increased visibility generated by a team brings more visitors into town.

Estimating the effect of team visibility on the attractiveness of a city as a destination is difficult, as both the location of teams and their decision to move are likely to be related to some of the factors that also make cities attractive to tourists (Siegfried and Zimbalist, 2000). I present the first evidence of a positive causal effect of team visibility on city travel by exploiting the random draw of the Union of European Football Associations (UEFA) Champions League soccer tournament, a European competition that takes place once a year. My identification strategy exploits a lottery that randomly allocates teams (and their cities) to different groups of the competition. This creates a unique "natural experiment" in which treatment is assigned to connections across entire cities.

In the first phase of the tournament, participating teams are randomly divided into groups of 4 , and have to play a 3-months round-robin tournament with the teams of their group. During this phase, the teams - and their home cities - are 
likely to get more mention in cities hosting group rivals, and the visibility of a city should therefore increase more in cities hosting teams in the same group than in other Champions League cities. As the groups are formed randomly, this setup allows to compare air travel between cities hosting teams in the same group (treated routes), to air travel between Champions League cities hosting teams assigned to different groups (control routes). The control routes represent a valid counterfactual for treated routes because the teams in these cities could have met, and did not by pure chance.

The group phase of the UEFA Champions League ends in early December and is followed by a break in the competition that lasts until early March. Looking at monthly data of intra European flights, I find that over the months from January to March cities hosting rivals in the group phase see an increase in monthly air traffic of 5 to 8 percentage points relative to routes across cities whose teams played in different groups. At the mean, this effect implies that between January and March around 2700 more people travel on treated routes. The effect fades away as the tournament proceeds to its final phase, and teams that were initially assigned to the same group no longer play against each other. Interestingly, I find a larger effect in cities that have a team which takes part in the Champions' League for the first time. Although the small number of such cities makes precise statements difficult, the result provides suggestive evidence that the group phase treatment has diminishing returns. 
The UEFA Champions League brings enormous media attention to the 32 participating soccer teams. Football is by far the most popular sport in Europe, and the UEFA Champions League is the major continental competition for European soccer teams. The competition is covered widely by national and local media, and the games are watched by millions of people across the continent. Participating clubs do not play any other continental competition during the season, and Champions League games are never played on days when domestic league or other continental competitions take place, which means that no other game competes for attention. The first phase of the tournament takes place during fall and lasts for around three months. During this phase participating teams are randomly divided into groups of 4 and teams in the same group play against each other twice.

My estimation strategy exploits the random formation of these groups and compares city travel between cities hosting teams in the same group with city travel between cities hosting teams in different groups. The advantage of this approach is that it eliminates the effect of participation in the UEFA Champions League, which is unlikely to be random. In effect, the approach allows to run a unique experiment where entire cities are either treated or control units.

Although the formation of groups is inherently random, I find that treated routes tend to be busier 9 to 3 months before the group phase starts (Figure 1). I clean the residual heterogeneity across treated and control routes by estimating all 
regressions with route fixed effects. Figure 2 shows that air traffic has identical distribution across treated and control routes once route fixed effects are accounted for. I show the robustness of my results to the inclusion of city-specific polynomial in time as well as several alternative methods of inference.

The paper proceeds as follows. The next section reviews the related literature. Section III explains the identification strategy and presents the data. Section IV shows that observable variables are balanced across treated and control routes. Section V presents the main results and section VI proves their robustness. Section VII discusses the results and concludes. 


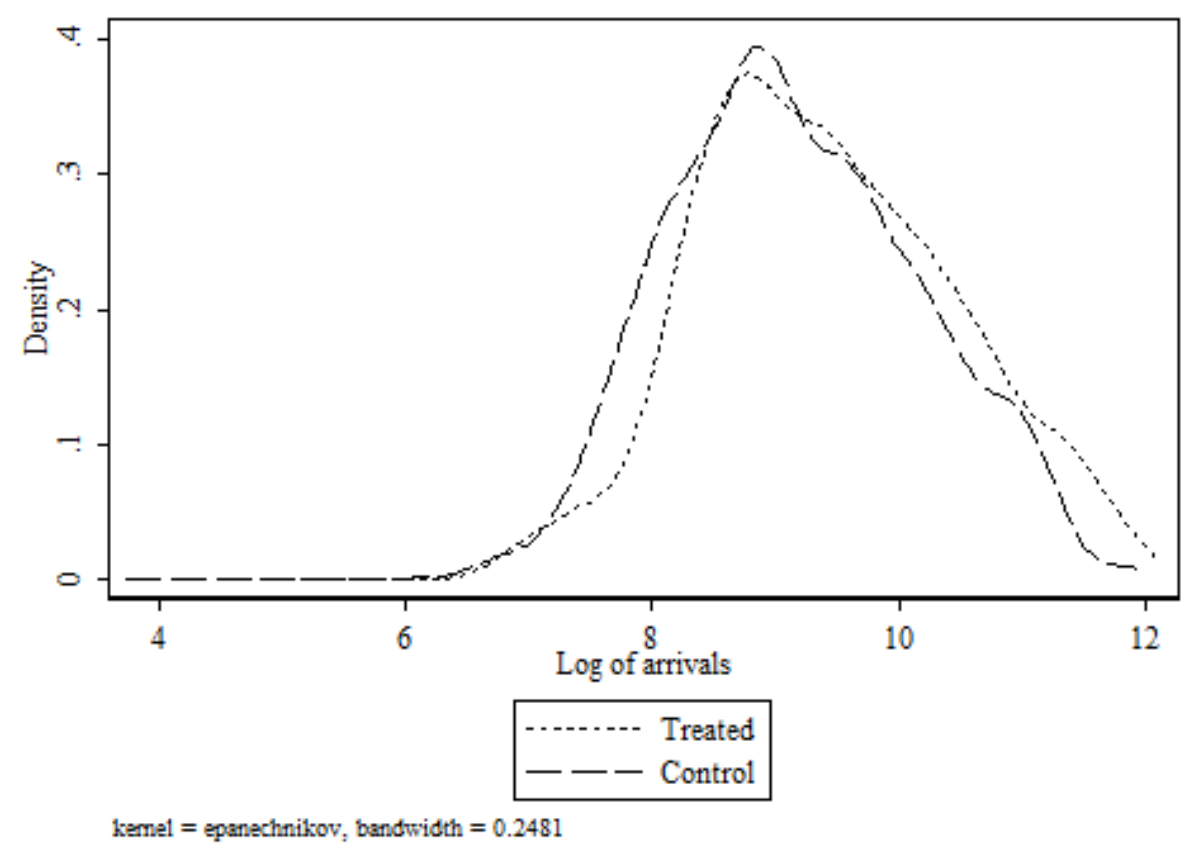

FIGURE 1. ARRIVALS IN JANUARY-JUNE ON ROUTES ACROSS CITIES TAKING PART TO THE CHAMPIONS LEAGUE GROUP PHASE IN THE FOLLOWING SEPTEMBER-DECEMBER (1998-2010)

Notes: There is one observation per route: number of arrivals is the average on the 2 directions. Treated routes have their team playing in the same group from September to December, control routes are routes across cities that could have met but eventually had their teams playing in different groups. Arrivals are observed in January-June before the Group phase takes place. I exclude all routes that: (i) could not have been treated given the seeding structure of the random draw and (ii) connect cities in Israel, Russia, Serbia, Turkey or Ukraine. 


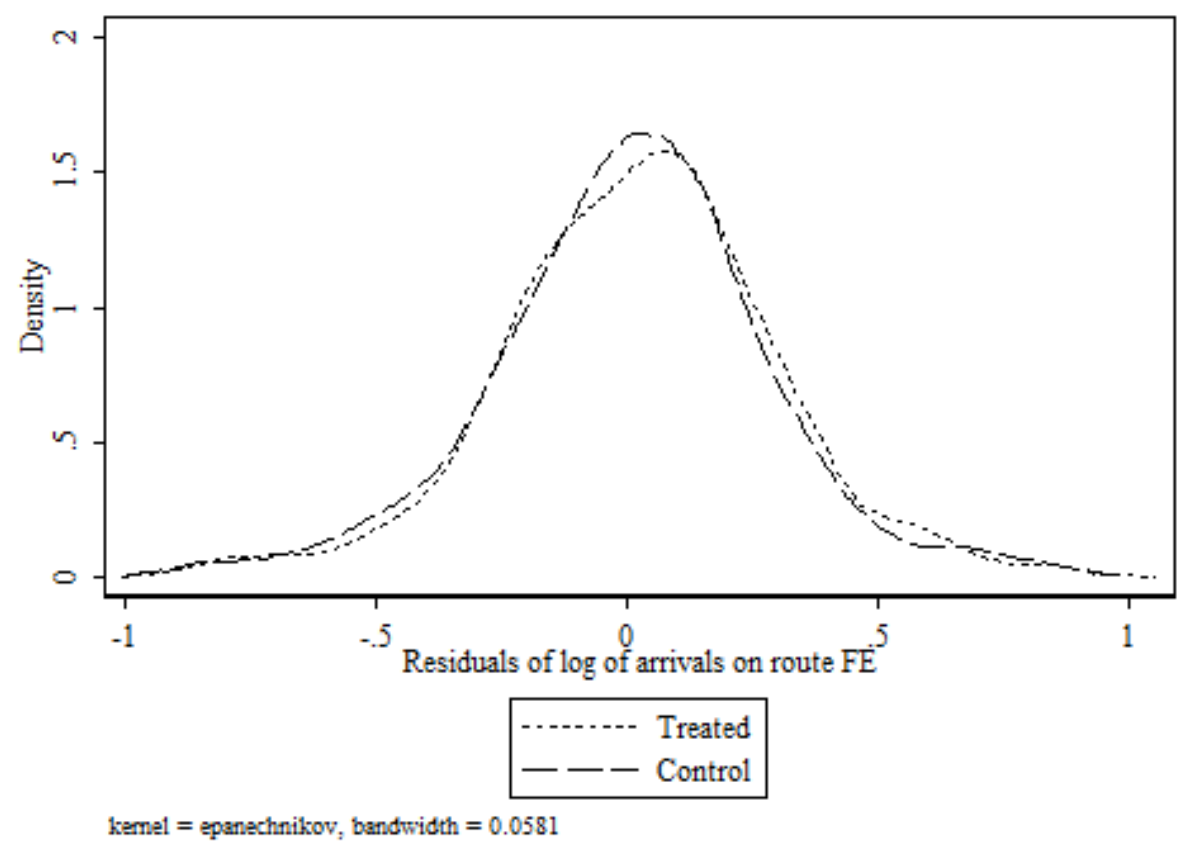

FIGURE 2. RESIDUALIZED ARRIVALS IN JANUARY-JUNE ON ROUTES ACROSS CITIES TAKING PART TO THE CHAMPIONS LEAGUE GROUP PHASE IN THE FOLLOWING SEPTEMBER-DECEMBER (1998-2010)

Notes: There is one observation per route, number of arrivals is the average on the 2 directions. Treated routes have their team playing in the same group from September to December, control routes are routes across cities that could have met but eventually had their teams playing in different groups. Arrivals are observed in January-June before the Group phase takes place. The figure plots the distribution of residuals from a regression on route fixed effects. I exclude all routes that: (i) could not have been treated given the seeding structure of the random draw and (ii) connect cities in Israel, Russia, Serbia, Turkey or Ukraine. The figure excludes observations with absolute change greater than 1 (for aesthetic reasons). 


\section{Related Literature}

This paper relates to a growing literature studying the impact of professional sports on tourism. Analysis of rate and occupancy of hotel rooms in the days around major sports event find generally positive effects on the day of the event but little anticipation (cf. the study of hotels in Charlotte, NC: Depken and Stephenson, 2018). The effects after the event are small and sometimes negative (as after winter games in Lapland: Falk and Vieru, 2020). Chikish et al. (2019) use NHL and NBA unexpected lockouts as natural experiments to study the effect of sports matches on hotel occupancy around a large sports arena in L.A. Their results indicate that these stoppages had if anything a positive effect on the hotels in the area. Similar results were found for Canadian cities by Lavoie and Rodrigues (2005). ${ }^{1}$

The presence of professional sport teams may affect income, wages and employment of local communities (Baade, 1996; Coates and Humphreys, 2003; Coates, 2007; Islam, 2017). Over the long run, direct and indirect effects will be incorporated in real estate prices, and Carlino and Coulson (2004) document higher house rents in cities with NFL franchises. ${ }^{2}$ Coates and Humphreys (2006) show that, when asked to vote on the public funding of a new stadium, people

\footnotetext{
1 A related literature has looked at tourists' expenditure during sports events: cf. Rudkin and Sharma (2018) for English Premier League games and Salgado-Barandela, Barajas and Sánchez-Fernández (2019) for the "sport portfolio" of a small town hosting several relatively medium-sized events.

2 Similarly, Propheter (2017) estimates higher rents in Brooklyn areas closer to the Barclays Sport Center.
} 
living in areas closer to the proposed site of the facility support the project more than people living farther away, suggesting a positive view of such projects by people directly affected. Some of the positive economic effects have been challenged (cf. Coates, Humphreys and Zimbalist, 2006) and the conventional wisdom is that sports franchises have at best a small effect on city growth.

The paper also speaks to the literature that has looked at the effect of "megaevents" such as the World Cup or Olympic Games. Fourie and Santana-Gallego (2011) find a positive effect for several (but not all) mega-events on tourist arrivals. More recently Baumann and Matheson (2018) document large increase in air travelers to Brazil during the 2014 FIFA World Cup, but argue that the effect is driven by the arrival of fans from one particular country which did good in that event (Argentina). Rose and Spiegel (2011) identify a positive and permanent effect of hosting Summer Olympics on the exports of a country, though their results have been challenged by Maennig and Richter (2012). Overall, the conclusions of this academic literature suggest that direct and indirect financial benefits do not justify the cost of organizing such events. ${ }^{3}$

Relative to previous work, this paper makes the following contributions. First, it introduces a new, credible identification to estimate the causal effect of media exposure associated with a large sport competition. Second, it documents a

\footnotetext{
3 In a similar vein, Baumann, Matheson and Muroi (2009) and Baumann and Matheson (2017) look at air arrivals to Hawaii during mega-events such as the NFL Pro Bowl to argue that economic benefits of such events do not justify public investments.
} 
persistent effect of sports events on air travel. Because I find persistence during months when the competition does not take place, the effect is likely to be a result of increased visibility from the Champions' League, not the air travel directly related to the competition.

\section{Identification and Data}

\section{A. Identification and Sample}

If a team increases the visibility of its home town, then we should observe visitors travel to the city after the club appears on high-profile international games. Moreover, the greatest number of visitors should come from cities where rival teams reside, and where the matches are arguably more salient.

The Champions League is the most important showcase for European football teams, and the group phase of the competition offers the opportunity to be under the spotlight repeatedly over a period of three months. If the visibility effect is greater in the cities where opposing teams reside, it is possible to test its existence by regressing visitor arrivals from city $j$ to city $i$ in month $m\left(V_{i j, m}\right)$ on an indicator of whether the two cities had their team matched in the previous group phase of the Champions League $\left(G_{i j}\right)$ :

$$
V_{t i m}=\beta_{0}+\beta_{1} G_{i j}+\varepsilon_{i j m} .
$$


In equation (1) $\beta_{1}$ is identified consistently because, within the population of all routes across cities with at least 1 team in the Champions League, $G_{i j}$ is randomly assigned. Notice that even observing $V_{i j, m}$ with no error, equation (1) is a conservative test for the visibility effect, because taking part to the Champions League is likely to increase the visibility of a city in all participating cities, regardless of the group in which they play. Since equation (1) compares visitors from cities with a team in the same group to visitors from cities with teams in different groups, it tests for the presence of an effect of being in the same group on top of the simple effect of taking part in the same edition of the Champions League.

Before discussing the data, it is useful to explain the format and timing of the Champions League. As of the 2012-13 edition, the group phase was played by 32 European teams divided in 8 groups of 4 teams each. Access to the group phase is reserved to the teams that performed best in their respective national leagues during the previous season. Once admitted to the group phase, every team is seeded into one of four pots according to its international standing: the eight strongest teams are seeded into pot number 1 , the next eight teams into pot number 2, and so on. After seeding, each of the 8 groups is made of exactly one team randomly drawn from every pot, with the only provision that teams from the same Football Federation should not play in the same group. The random draw is 
performed publicly in front of the press at the end of August. Once the groups are formed, between September and December each club has to play twice against each of the other 3 teams in its group: once at home and once as visitor.

Games are always played on Tuesday or Wednesday, and they are broadcasted live on national televisions in prime time. These matches, and the media attention that they create in the two cities where they take place, is my treatment. Since teams assigned to different groups have no occasion to play against each other between September and December, and since only one group phase match was forfeited in the years I consider, compliance is always perfect. ${ }^{4}$ After the conclusion of the group phase in early December, the first two teams of every group advance to the final phase: this has the knock-out format and proceeds from the round of sixteen in March to the final in May. ${ }^{5}$

The rules of the random draw imply that not all routes across Champions League cities are valid controls for treated routes. Teams in the same pot and teams from the same country never play in the same group: since routes across the cities of these teams could not have been treated, I exclude them throughout. Teams that have been seeded in the same pot tend to be of similar strength, and so this approach makes sure that routes across cities with two very strong (or two

\footnotetext{
4 The forfeited match is A.S. Roma versus Dynamo Kyiv F.C., that was scheduled for the $15^{\text {th }}$ of September 2004. For reasons discussed shortly, I exclude all routes that connect cities in Ukraine, and for this reason this observation is never part of the sample analyzed.

5 The interested reader may refer to appendix $\mathrm{C}$ for additional details on the structure and history of the competition.
} 
very weak) teams are not over represented in the control group. Since the strength of a team might be correlated with the economic performance of its home town, excluding these routes makes sure that results are not biased by the different composition of treated and control groups. On the other hand, teams coming from the same country never play in the same group in the Champions League, but have to play against each other in their national league. Since also these national games have the potential to increase the visibility of a city, dropping these routes makes sure that results are not biased downward by the inclusion of these routes among the controls.

In addition to these exclusions, I always omit treated and control routes to and from UEFA countries that require a passport and/or a visa to enter (these are: Israel, Serbia, Russia, Turkey and Ukraine). I do so because travel to these countries requires significantly more time and effort than travel within the Schengen Area, and these costs are likely to offset any boost coming from the Champions League. Although randomization was performed using teams from these countries too, between 1998-99 and 2010-11 only 13 percent of participants came from these nations, and their exclusion makes no difference in terms of balance of the remaining treated and control routes. Inclusion of these routes has two consequences on the results shown later. First, the distribution of variables across treatment and control routes is more balanced when these routes are 
included. Second, coefficients from all regressions are less precise and somewhat smaller (but still significant).

\section{B. Data}

High frequency data on city-to-city number of visitors is scarce, and $V_{i j, m}$ in equation (1) can be observed only imperfectly. I proxy $V_{i j, m}$, the number of visitors from city $j$ to city $i$ in month $m$, with (the logarithm of) $P_{i j, m}$, the number of arrivals from all airports serving city $j$ to all airports serving city $i$ in month $m$. These data are available from Eurostat at monthly frequency since 1998, so I will focus on all Champions League editions between the 1998-99 and the 2010-11. Data on all Champions League games comes from the UEFA official website. See appendix A for further details.

Studying the visibility effect on air traffic alone would not be a limitation if visitors traveling with other modes of transport are affected in similar ways. In practice, the relative importance of different modes of transport depends on the relative position of two cities, so that the visibility effect is likely to have heterogeneous effects across different routes and modes of transport. Random assignment implies that estimated coefficients are consistent estimates of the Average Treatment Effect (ATE) of the Champions League on air traffic. Since 
most Europeans travel abroad by plane, this is a relevant effect to estimate. ${ }^{6}$ Moreover, if we were willing to assume that on average the Champions League effect is the same for other modes of transport, then the estimated coefficient would be a consistent estimate of the proportional effect of the Champions League on overall travel. ${ }^{7}$

One final reason to consider results with air travel as a lower bound is the following. Not all routes have equal capacity, and affected visitors might find it convenient to fly across airports that do not serve directly the cities in the Champions League (for instance, tourists going to Turin may land in the larger airport of Milan for convenience). Since I only look at the airports directly serving cities with teams in the Champions League, and do not control for potential stopovers or airports in nearby cities, my estimates would be biased downward if the effect spills over to routes that are classified as controls, or if some of the effect travels on routes that I do not consider.

\footnotetext{
${ }^{6}$ Among the countries considered, across any pair of countries for which both air and train traffic is available, there was a median of 11.2 air travelers for every passenger arriving by train between 2004 and 2010. For countries that are connected via sea, the median ratio of air to boat arrivals over the same period was 2.9. There are no similar statistics on intra European road traffic, but given that within the countries considered the median ratio of passenger-Km transported by car (by coach) to those transported by train is $11.2(1.6)$, air traffic is likely to be at least as important as car travel, and several times more relevant than either train, coach or boat. Notice moreover that these numbers are likely to be lower bounds of the relevance of air traffic within Europe, because they are computed only for country pairs for which a direct connection is active (either by train or via sea). For several country pairs in the sample no such link exists, and on many routes airplanes are simply the only practical mode of transport available.

${ }^{7}$ In order to estimate the ATE of the Champions League on the overall number of travelers one would still need to multiply the estimated proportional change by the average overall travel across all routes in the sample. Since city-level information on non airborne travel is not available, these computations are not feasible.
} 


\section{Balancedness}

This section documents the balance between treated and control pairs. The first line of Table 1 shows that the baseline value of the variable of interest is not balanced across treated and control routes before treatment is assigned. Average arrivals between January and June are $0.21 \mathrm{log}$ points greater on routes that will be treated the following September $(p$-value $=0.016$ ). Figure 1 shows that also the distribution of this variable is different across treated and controls (the Kolmogorov-Smirnov test rejects the null of identical distributions at the 0.1 percent level). Since between January and June most participants of the Champions League edition that starts in September are still to be decided, these tests suggest that treated routes tend to be busier than control routes always.

Although the formation of groups is inherently random, cities that send their teams more often to the Champions League are more likely to have their teams matched together, and at the same time might be richer and have busier routes. In general, if unobservable characteristics of two cities affect both the average air traffic and the likelihood of their teams to meet during the group phase of the Champions League, the estimates of the Champions League effect will be inconsistent. This is especially true when the dependent variable is air arrivals, 
because air traffic is extremely persistent, ${ }^{8}$ and in these cases Bruhn and McKenzie (2009) insist that consistency of estimates is warranted only when also the baseline value of the outcome of interest is balanced across treated and controls.

I address the heterogeneity in the baseline value of air arrivals across treated and controls by exploiting the panel structure of my data. In Figure 2 I plot the distributions of the residuals of a regression of air arrivals between January and June before the group phase on route fixed effects (FE). The figure shows that the distribution of these residuals in treated routes is very similar to the distribution in control routes. The Kolmogorov-Smirnov tests can not reject the null of identical distributions $(p$-value $=0.194)$. Even though the test has low power $(\mathrm{Kim}$ and Whitt, 2015), both its result and visual inspection of Figure 2 provide initial support to the identification strategy, as they suggest that the inclusion of route FE make treated and control routes comparable. A more robust test is a comparison of average arrivals in the months before treatment conditional on route fixed effects: row 3 on Table 1 reports this test, which fails to reject the null of no difference $(p$-value $=0.761)$.

The rest of Table 1 shows that treated and control pairs are balanced also with respect to other observable characteristics. Because the units of observation are

\footnotetext{
${ }^{8}$ In the sample considered, a univariate regression of log arrivals on its value 12 months before explains 93 percent of total variability.
} 
pairs of cities, I use dyadic regressions (cf. Fafchamps and Gruber 2007a): I check the balance of treated and control routes with respect to both the average and the absolute difference of the variables of the two cities on a route. The intuition is that both the levels and the difference of these variables may correlate with air travel across the two cities. See Appendix B for details. 
TABle 1 - Balance of TReated AND Control Routes.

\begin{tabular}{|c|c|c|c|c|c|}
\hline \multirow[b]{2}{*}{ Variable } & \multicolumn{2}{|c|}{ Observations } & \multicolumn{2}{|c|}{ Mean } & \multirow[b]{2}{*}{$\begin{array}{c}p \text {-value } \\
(\mathrm{T}=\mathrm{C})\end{array}$} \\
\hline & Treated & Control & Treated & Control & \\
\hline \multicolumn{6}{|c|}{ PANEL A - Dependent variable $(\log P)$} \\
\hline \multicolumn{6}{|c|}{ Arrivals (January-June before group phase, logs) } \\
\hline Average & 162 & 1061 & 11.11 & 10.9 & $0.016^{* *}$ \\
\hline Absolute difference & 162 & 1061 & 6.6 & 6.36 & $0.008 * * *$ \\
\hline \multicolumn{6}{|c|}{ Route FE regression residuals (January-June before group phase, logs) } \\
\hline Average & 162 & 1061 & 0.01 & 0.00 & 0.761 \\
\hline Absolute difference & 162 & 1061 & 0.01 & 0.00 & 0.696 \\
\hline \multicolumn{6}{|c|}{ Change in arrivals (January-June before group phase, logs) } \\
\hline Average & 137 & 933 & $6.80 \%$ & $4.40 \%$ & 0.230 \\
\hline Absolute difference & 137 & 933 & $10.30 \%$ & $2.50 \%$ & $0.081^{*}$ \\
\hline \multicolumn{6}{|c|}{ PANEL B - Selection } \\
\hline \multicolumn{6}{|c|}{ Routes with non missing air-traffic (September-December) } \\
\hline & 3544 & 23312 & $15.60 \%$ & $14.90 \%$ & 0.248 \\
\hline \multicolumn{6}{|c|}{ PANEL C - Tourism } \\
\hline \multicolumn{6}{|c|}{ Touristic nights by residents (year of the match, logs) } \\
\hline Average & 112 & 720 & 15.73 & 15.66 & 0.286 \\
\hline Absolute difference & 112 & 720 & 1.26 & 1.29 & 0.746 \\
\hline \multicolumn{6}{|c|}{ Touristic nights by residents ( 1 year before the match, logs) } \\
\hline Average & 109 & 703 & 15.7 & 15.63 & 0.351 \\
\hline Absolute difference & 109 & 703 & 1.28 & 1.3 & 0.809 \\
\hline \multicolumn{6}{|c|}{ Change in touristic nights by residents (year of the match) } \\
\hline Average & 109 & 703 & $2.50 \%$ & $2.20 \%$ & 0.658 \\
\hline Absolute difference & 109 & 703 & $9.90 \%$ & $10.00 \%$ & 0.964 \\
\hline \multicolumn{6}{|c|}{ Touristic nights by non residents (year of the match, logs) } \\
\hline Average & 112 & 720 & 15.89 & 15.85 & 0.621 \\
\hline Absolute difference & 112 & 720 & 1.44 & 1.52 & 0.465 \\
\hline \multicolumn{6}{|c|}{ Touristic nights by non residents ( 1 year before the match, logs) } \\
\hline Average & 109 & 703 & 15.84 & 15.81 & 0.586 \\
\hline Absolute difference & 109 & 703 & 1.41 & 1.53 & 0.311 \\
\hline \multicolumn{6}{|c|}{ Change in touristic nights by non residents (year of the match) } \\
\hline Average & 109 & 703 & $4.20 \%$ & $3.70 \%$ & 0.537 \\
\hline Absolute difference & 109 & 703 & $6.50 \%$ & $7.60 \%$ & 0.138 \\
\hline
\end{tabular}

Notes: The sample include all treated and control routes for which information on reported variable is available but excludes all routes to and from Israel, Russia, Serbia, Turkey and Ukraine.

Source: Author calculations.

$* * *$ Significant at the 1 percent level.

** Significant at the 5 percent level.

* Significant at the 10 percent level. 
TABLE 1(CONTINUED) - BALANCE OF TREATED AND CONTROL Routes.

\begin{tabular}{|c|c|c|c|c|c|}
\hline \multirow[b]{2}{*}{ Variable } & \multicolumn{2}{|c|}{ Observations } & \multicolumn{2}{|c|}{ Mean } & \multirow[b]{2}{*}{$\begin{array}{c}p \text {-value } \\
(\mathrm{T}=\mathrm{C})\end{array}$} \\
\hline & Treated & Control & Treated & Control & \\
\hline \multicolumn{6}{|c|}{ PANEL D - Economy } \\
\hline \multicolumn{6}{|c|}{ Income per capita (year of the match, logs) } \\
\hline Average & 8 & 49 & 9.8 & 9.77 & 0.577 \\
\hline Absolute difference & 8 & 49 & 0.28 & 0.28 & 0.887 \\
\hline \multicolumn{6}{|c|}{ Income per capita ( 3 years before the match, logs) } \\
\hline Average & 17 & 105 & 9.81 & 9.78 & 0.630 \\
\hline Absolute difference & 17 & 105 & 0.36 & 0.41 & 0.454 \\
\hline \multicolumn{6}{|c|}{ Income per capita growth (during the match) } \\
\hline Average & 5 & 33 & $1.80 \%$ & $0.40 \%$ & 0.548 \\
\hline Absolute difference & 5 & 33 & $10.20 \%$ & $13.10 \%$ & 0.436 \\
\hline \multicolumn{6}{|c|}{ Unemployment rate (year of the match) } \\
\hline Average & 54 & 294 & $9.10 \%$ & $8.90 \%$ & 0.636 \\
\hline Absolute difference & 54 & 294 & $5.20 \%$ & $4.30 \%$ & 0.135 \\
\hline \multicolumn{6}{|c|}{ Unemployment rate ( 3 years before the match) } \\
\hline Average & 69 & 387 & $8.60 \%$ & $8.30 \%$ & 0.485 \\
\hline Absolute difference & 69 & 387 & $4.80 \%$ & $4.40 \%$ & 0.434 \\
\hline \multicolumn{6}{|c|}{ Change in unemployment rate (year of the match) } \\
\hline Average & 35 & 190 & $1.10 \%$ & $0.60 \%$ & 0.323 \\
\hline Absolute difference & 35 & 190 & $5.50 \%$ & $4.20 \%$ & 0.106 \\
\hline \multicolumn{6}{|c|}{ PANEL E - Geography } \\
\hline Distance $(\log s)$ & 113 & 668 & 6.76 & 6.76 & 1.000 \\
\hline \multicolumn{6}{|l|}{ Cities are capital } \\
\hline Both & 139 & 860 & $18.00 \%$ & $17.20 \%$ & 0.823 \\
\hline Only 1 & 139 & 860 & $50.40 \%$ & $46.50 \%$ & 0.399 \\
\hline \multicolumn{6}{|c|}{ Cities are on an island (e.g. Great Britain, Cyprus) } \\
\hline Both & 139 & 860 & $0.00 \%$ & $0.50 \%$ & 0.421 \\
\hline Only 1 & 139 & 860 & $29.50 \%$ & $31.40 \%$ & 0.654 \\
\hline \multicolumn{6}{|l|}{ Cities are in a landlocked country } \\
\hline Both & 139 & 860 & $0.00 \%$ & $0.10 \%$ & 0.688 \\
\hline Only 1 & 139 & 860 & $10.10 \%$ & $10.00 \%$ & 0.979 \\
\hline \multicolumn{6}{|c|}{ Cities are in a Mediterranean country } \\
\hline Both & 139 & 860 & $14.40 \%$ & $11.30 \%$ & 0.290 \\
\hline Only 1 & 139 & 860 & $48.20 \%$ & $47.60 \%$ & 0.888 \\
\hline
\end{tabular}

Notes: The sample include all treated and control routes for which information on reported variable is available but excludes all routes to and from Israel, Russia, Serbia, Turkey and Ukraine.

Source: Author calculations.

*** Significant at the 1 percent level.

** Significant at the 5 percent level.

* Significant at the 10 percent level. 
TABLE 1(CONTINUED) - BALANCE OF TREATED AND CONTROL Routes.

\begin{tabular}{|c|c|c|c|c|c|}
\hline \multirow[b]{2}{*}{ Variable } & \multicolumn{2}{|c|}{ Observations } & \multicolumn{2}{|c|}{ Mean } & \multirow[b]{2}{*}{$\begin{array}{c}p \text {-value } \\
(\mathrm{T}=\mathrm{C})\end{array}$} \\
\hline & Treat. & Control & Treat. & Control & \\
\hline \multicolumn{6}{|c|}{ PANEL F - Demography } \\
\hline \multicolumn{6}{|l|}{ Population (year of the game, logs) } \\
\hline Average & 95 & 525 & 14.11 & 14.07 & 0.546 \\
\hline Absolute difference & 95 & 525 & 1.33 & 1.33 & 0.993 \\
\hline \multicolumn{6}{|c|}{ Population ( 3 year before the game, logs) } \\
\hline Average & 91 & 530 & 14.1 & 14.06 & 0.629 \\
\hline Absolute difference & 91 & 530 & 1.49 & 1.43 & 0.643 \\
\hline \multicolumn{6}{|c|}{ Population growth (year of the match) } \\
\hline Average & 75 & 426 & $1.70 \%$ & $2.00 \%$ & 0.292 \\
\hline Absolute difference & 75 & 426 & $3.80 \%$ & $3.50 \%$ & 0.516 \\
\hline \multicolumn{6}{|c|}{ Percent population aged 20 to 35 (year of the match) } \\
\hline Average & 81 & 475 & $23.40 \%$ & $23.30 \%$ & 0.706 \\
\hline Absolute difference & 81 & 475 & $4.10 \%$ & $4.70 \%$ & 0.116 \\
\hline \multicolumn{6}{|c|}{ Percent population aged 20 to 35 ( 3 years before the match) } \\
\hline Average & 63 & 358 & $23.20 \%$ & $23.30 \%$ & 0.701 \\
\hline Absolute difference & 63 & 358 & $3.80 \%$ & $4.00 \%$ & 0.538 \\
\hline \multicolumn{6}{|c|}{ Change in percent population aged 20 to 35 (year of the match) } \\
\hline Average & 46 & 269 & $-0.70 \%$ & $-0.70 \%$ & 0.976 \\
\hline Absolute difference & 46 & 269 & $1.30 \%$ & $1.40 \%$ & 0.577 \\
\hline \multicolumn{6}{|c|}{ Percent non national, EU residents (year of the match) } \\
\hline Average & 40 & 205 & $4.60 \%$ & $4.40 \%$ & 0.603 \\
\hline Absolute difference & 40 & 205 & $5.70 \%$ & $5.30 \%$ & 0.644 \\
\hline \multicolumn{6}{|c|}{ Percent non national, EU residents ( 3 years before the match) } \\
\hline Average & 45 & 225 & $4.00 \%$ & $3.60 \%$ & 0.371 \\
\hline Absolute difference & 45 & 225 & $5.00 \%$ & $4.60 \%$ & 0.636 \\
\hline \multicolumn{6}{|c|}{ Change in percent non national, EU residents (year of the match) } \\
\hline Average & 28 & 153 & $0.90 \%$ & $0.70 \%$ & 0.313 \\
\hline Absolute difference & 28 & 153 & $1.00 \%$ & $0.70 \%$ & $0.063 *$ \\
\hline \multicolumn{6}{|c|}{ Cities speak a romance language (e.g. Italian, Spanish,...) } \\
\hline Both & 139 & 860 & $31.70 \%$ & $26.20 \%$ & 0.176 \\
\hline Only 1 & 139 & 860 & $41.70 \%$ & $41.50 \%$ & 0.962 \\
\hline \multicolumn{6}{|c|}{ Cities speak a germanic language (e.g. German, English,...) } \\
\hline Both & 139 & 860 & $11.50 \%$ & $15.30 \%$ & 0.237 \\
\hline Only 1 & 139 & 860 & $51.80 \%$ & $43.30 \%$ & $0.060 *$ \\
\hline
\end{tabular}

Notes: The sample include all treated and control routes for which information on reported variable is available but excludes all routes to and from Israel, Russia, Serbia, Turkey and Ukraine.

Source: Author calculations.

*** Significant at the 1 percent level.

** Significant at the 5 percent level.

* Significant at the 10 percent level. 
Panel B of Table 1 shows that out of all the routes across cities that could have met but did not, 14.9 percent have non missing air data for both ways of the route during the months of the group phase. This number is similar to the proportion of routes across cities that had two teams playing in the same group ( $p$-value $=$ 0.248 ) and suggests that not observing all air routes is not a source of concern.

Panel $\mathrm{C}$ of Table 1 looks at tourism in the regions of the cities of the two teams, and it shows that tourist nights spent by residents and non-residents in the two years leading to the treatment do not differ systematically between treated and controls. Panel D looks at economic variables (income and unemployment) and Panel E looks at geography (distance between cities, capital status and location: on an island or landlocked): none of these variables are significantly different between treated and control routes. Finally, Panel F of Table 1 turns to demographics: population, share of people 20-35 years old, non-national EU residents and language: treated routes are only more likely to have one city speaking a Germanic language $(p$-value $=0.060)$.

The tests in Table 1 show a strong balance between treated and control routes. Out of 60 tests, three are significant at the 10 percent level and only one at the 5 percent level: less than the nominal probability of these tests. A joint test that allows correlation across these variables cannot reject the null of identical means: when I standardize all variables and run a single regression on the treatment 
dummy, the coefficient of this dummy is not significant $(p$-value $=0.284)$. Since in this stacked regression I use standard errors clustered at the route-year level, this procedure tests for significant differences across treatment and control routes while allowing errors of different variables to be correlated within a single routeyear. ${ }^{9}$ Taken together, these results confirm that treatment is randomly assigned with respect to both time invariant and time varying characteristics, and that also pre trends do not differ significantly across treated and control routes.

\section{Results}

\section{A. Event-Study Analysis}

I start by documenting the effect of being drawn into the same Champions' League group on air arrivals with an event-study strategy. I estimate:

$$
\begin{aligned}
\log P_{i j, m} & =\alpha_{i j, m}+\delta_{t}+\mu_{m} \times t+\sum_{l=-6}^{12} \gamma_{l} G_{i j, m-l}+ \\
& +\sum_{c} \phi^{c}\left(c_{i}+c_{j}\right) \times t+\sum_{c} \psi^{c}\left(c_{i}-c_{j}\right) \times t+e_{i j, m},
\end{aligned}
$$

Where I regress the log number of passengers travelling from city $i$ to city $j$ in month $m$ on $G_{i j, m}$ : a dummy equal to 1 if in that month teams from the two cities play a game of the group phase of the Champions' League. I include 6 leads and

\footnotetext{
${ }^{9}$ Estimation of 60 Seemingly Unrelated Regressions (SUR) is not feasible in this context because the covariance matrix of errors is singular.
} 
12 lags of this dummy $\left(G_{i j, m-l}: l=-6, \ldots,+12\right)$ to study the dynamics. ${ }^{10}$ The regression controls for route-month fixed effects $\left(\alpha_{i j}\right)$, year fixed effects $\left(\delta_{t}\right)$, and time trends specific to each month $\left(\mu_{m} \times t\right)$ and country of origin and destination $\left(\sum_{c}\left(c_{i}+c_{j}\right) \times t\right.$ and $\left.\sum_{c}\left(c_{i}-c_{j}\right) \times t\right){ }^{11}$

Figure 3 plots $\gamma_{l}$ from Equation (2). Conditional on route-month fixed effects treatment is as good as random: thus, all $\gamma_{l}$ have causal interpretation. Figure 3 suggests three conclusions. First, on average, each Champions' League match increases city-to-city monthly air travel by 7.5 percentage points ( $p$-value $<$ 0.000). The shock is sizable: on a monthly average of 16545 arrivals, this equals 1238 passengers more for every match, 0.06 standard deviations or almost 7 full Airbus A320. Many of these extra arrivals are likely to be fans following their teams in the away matches: this first result confirms the importance of the groupphase match as a shock to city-to-city air travel.

Second, the spike is exactly on the month of the match, and all coefficients before the match are not significantly different from 0 , neither alone nor jointly $(F$ $=1.26 ; p$-value $=0.271)$. This confirms the absence of pre-trends and supports the identification strategy.

\footnotetext{
${ }^{10}$ The number of leads and lags spans half a year before and one year after the event. Figures similar to Figure 3 can be produced with any number of leads and lags. Standard errors are clustered at the route-year-month level. See Section VI.B for a discussion of robust inference.

11 Equation (2) is a directional dyadic regression (because $\log P_{i j, m} \neq \log P_{j i, m}$ ). I follow Fafchamps and Gruber (2007b) and impose that the effect of countries trends on air travel be symmetric. I do this with $\sum_{c} \phi^{c}\left(c_{i}+c_{j}\right) \times t$ and $\sum_{c} \psi^{c}\left(c_{i}-c_{j}\right) \times$ $t$. To see how this works, take all arrivals to and from Italy $\left(c_{i}=I T_{i}\right)$ : for this country, $\phi^{I T}$ captures the average trend of passengers to and from all Italian airports in the sample, while $\psi^{I T}$ picks the average trend of passengers for routes whose origin is in Italy. Symmetry requires that the average trend of passengers for routes that have destination in Italy be equal to minus the average trend for routes with origin there. The two terms in (2) impose this condition.
} 


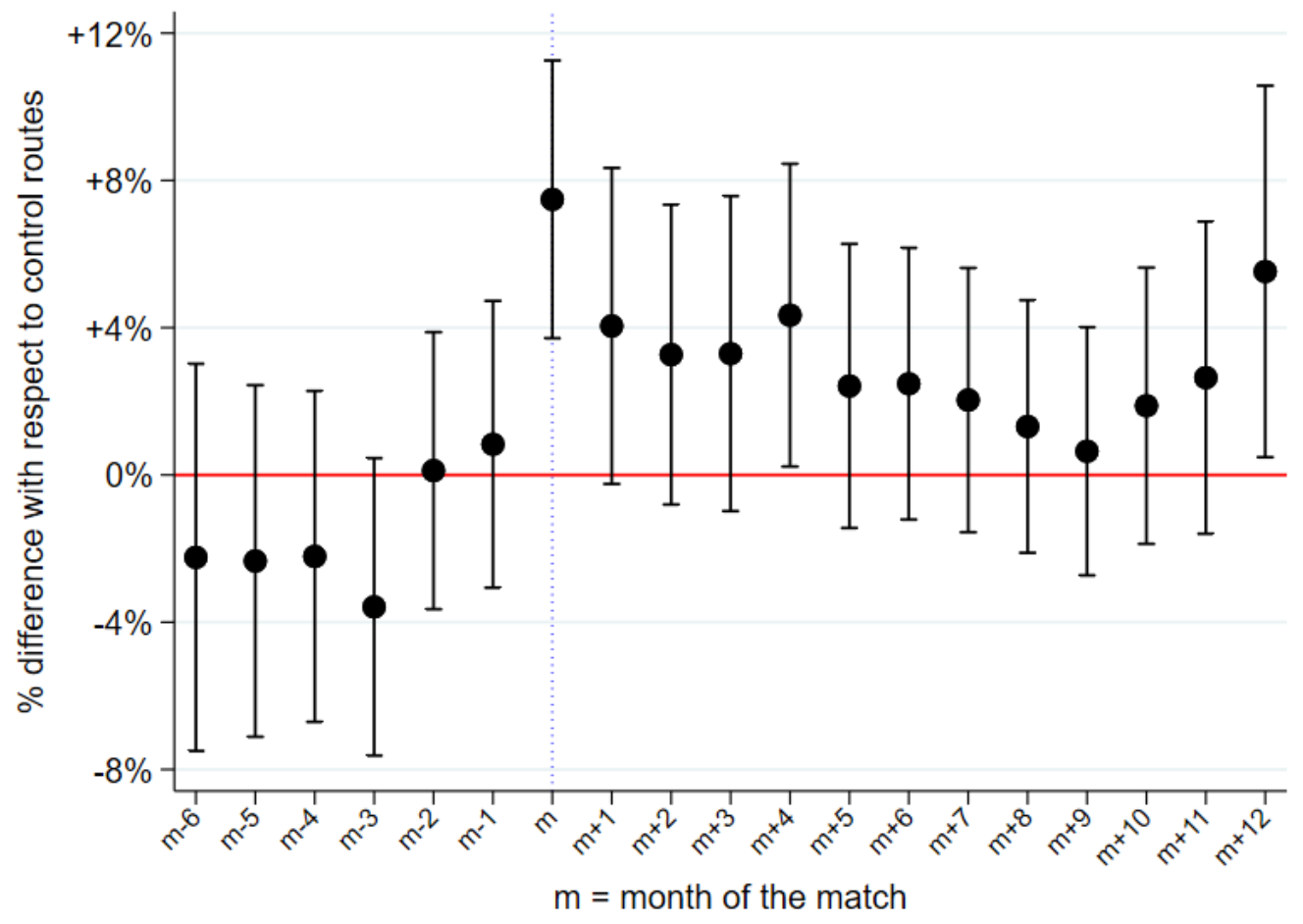

FIGURE 3. THE EFFECT ON THE MONTH OF THE MATCH

Notes: The figure plots estimates of $\gamma_{l}$ from regression (2) $(l=-6,-5, \ldots,+12)$. These coefficients represent the proportional difference in arrivals from city $j$ to city $i$ on treated routes relative to control routes. The coefficient in $m\left(\gamma_{0}\right)$ is the effect on the month in which a group phase match is played. The figure also plots effects 6 months before the game $(m-$ 6) until 12 months after it $(m+12)$. 95 percent confidence intervals calculated using standard errors clustered at the routemonth-year level are reported around the estimates. The number of observations is 17922: these are all routes across cities that had at least 1 team taking part in the Champions' League group phase either in the current or in the previous year, but excludes routes that: (i) could not have been treated given the seeding structure of the random draw; (ii) connect cities in Israel, Russia, Serbia, Turkey or Ukraine and (iii) had their teams met in the later stages of the competition either in the current or in the previous edition of the Champions' League. The dependent variable $\left(\log P_{i j, m}\right)$ has the top and bottom 0.5 percent of observations winsorized. Additional controls are year fixed effects, and trends specific to every month and to every country of origin and of destination. See text for details. 
Third, Figure 3 suggests that treated routes stay relatively busier during the months following the game. A joint test of the first 8 lags of $G_{i j m-l}$ rejects the null of no effect $(F=3.09$; $p$-value $=0.002)$, but only the fourth lag is individually significant at the 5 percent level. Because the two group-phase matches are played in any of the last four months of the year, it is possible that the event-study analysis does not pick up the effect on specific months precisely. Moreover, the event-study treats these two matches as two separate events, while the "treatment" that matters is likely to be the whole group phase. In the next section I explore this possibility with separate regressions for every month.

\section{B. The Effect after the Group Phase}

In order to test more carefully the hypothesis that air travel increases more on treated routes after the group phase ends, I focus on one month at a time, and for every month between the end of the group phase and start of following edition I estimate a separate regression of the form:

$$
\begin{aligned}
\log P_{i j, m} & =\alpha_{i j}+\delta_{t}+\beta \cdot G_{i j}+ \\
& +\sum_{c} \phi^{c}\left(c_{i}+c_{j}\right) \cdot t+\sum_{c} \psi^{c}\left(c_{i}-c_{j}\right) \cdot t+e_{i j, m},
\end{aligned}
$$

where $G_{i j}=1$ if the teams from the two cities played in the same group in the last edition of the Champions League and the meaning of other symbols is the same as in regression (2). Consistency of $\beta$ is warranted by random assignment of $G_{i j}$ and the inclusion of route fixed effects $\alpha_{i j}$. 
TABLE 2 - EFFECT OF PLAYING IN THE SAME GROUP OF THE CHAMPIONS LEAGUE DURING THE FOLLOWING MONTHS.

\begin{tabular}{|c|c|c|c|c|c|c|}
\hline & $\beta$ & s.e. & Obs. & $\begin{array}{l}\text { Route } \\
\text { FE }\end{array}$ & $\begin{array}{c}\text { Year FE \& } \\
\text { country trends }\end{array}$ & $\begin{array}{l}\text { Month FE \& } \\
\text { month trends }\end{array}$ \\
\hline Month of the match ${ }^{a}$ & $0.067 * * *$ & $(0.016)$ & 6136 & Yes & Yes & Yes \\
\hline January & $0.084 * *$ & $(0.035)$ & 1344 & Yes & Yes & No \\
\hline February & $0.064 * *$ & $(0.032)$ & 1346 & Yes & Yes & No \\
\hline $\operatorname{March}^{\mathrm{b}}$ & $0.062 * *$ & $(0.028)$ & 1340 & Yes & Yes & No \\
\hline April $^{\text {b }}$ & 0.045 & $(0.030)$ & 1358 & Yes & Yes & No \\
\hline May ${ }^{\mathrm{b}}$ & 0.042 & $(0.030)$ & 1354 & Yes & Yes & No \\
\hline June & 0.030 & $(0.023)$ & 1584 & Yes & Yes & No \\
\hline July & 0.033 & $(0.024)$ & 1584 & Yes & Yes & No \\
\hline August & 0.019 & $(0.025)$ & 1584 & Yes & Yes & No \\
\hline
\end{tabular}

Notes: The table reports estimates of $\beta$ in equation (3). The sample includes all routes across cities that had at least 1 team taking part in the Champions League group phase during the current edition. I exclude all routes that: (i) could not have been treated given the seeding structure of the random draw; (ii) connect cities in Israel, Russia, Serbia, Turkey or Ukraine and (iii) had their teams met in the later stages of the competition either in the current or in the previous edition of the Champions' League. The dependent variable $\left(\log P_{i j, m}\right)$ has the top and bottom 0.5 percent of observations winsorized. Standard errors in parentheses are clustered at the routemonth-year level. See text for details.

Source: Author calculations.

${ }^{a}$ September through December. ${ }^{b}$ Knock-out phase.

*** Significant at the 1 percent level.

** Significant at the 5 percent level.

* Significant at the 10 percent level. 
Since the format of the competition has changed over the years I consider, and since the likelihood of teams to access the group phase evolves overtime according to the UEFA ranking of their home country, both year and country trends could be correlated with the likelihood that a specific team accesses the group phase (see Appendix $\mathrm{C}$ for a discussion of how country rankings affect the likelihood of accessing the group phase, and how UEFA computes them). In practice neither years nor country trends are correlated with the treatment: in a regression of $G_{i j}$ on route-fixed effects, years fixed effects and country trends, it is not possible to reject the null of joint insignificance of year fixed effects and country trends $(F=0.55 ; p$-value $=0.979)$. I include these controls to improve precision: point estimates of $\beta$ are barely affected when only route fixed effects $\left(\alpha_{i j}\right)$ are included.

Table 2 shows estimates of (3) for the month of the match and for all months from January through August. In all regressions standard errors are clustered at the route-month-year level. ${ }^{12}$ The sample consists of all international routes across cities that could have met in the Champions League group phase between the 1998-99 and 2010-11 editions but it excludes routes across cities that have their teams playing a match during the Champions League knock-out stage either that year or the year before. I exclude these routes because knock-out phase matches are a bigger shock to air traffic than group phase matches and teams playing in the

\footnotetext{
12 Section VI.B discusses clustering and alternative inference methods.
} 
same group are less likely to meet again at later stages: as a result, inclusion of these routes biases estimates downwards. ${ }^{13}$

Table 2 indicates that playing in the same group of the Champions League increases air travel both on the month of the match (row 1) and in the first three months following the end of the group phase. The effect in January equals 0.08 standard deviations in passenger arrivals in that month; the effects in both February and March equal 0.06 standard deviations of arrivals in these two months. The effect is smaller and not significant by April, when the knock-out phase reaches its most important games (quarter of finals and semi finals), and it disappears before the start of the new season in September. The effect is also economically relevant: in the first 3 months of the year, the estimates imply 996 more passengers in January, 775 in February and 921 in March at the mean number of arrivals for these three months (11794, 12089 and 14798 respectively). Overall, two 90-minutes matches played during the fall attract 2692 visitors during the first three months of the year: 7 percent of average traffic in this period.

Notice that the positive effects shown in the three months after the end of the group phase is not confounded by other matches played during the same period:

\footnotetext{
13 The probability to meet a team from the same group is 0 for the round of sixteen, and very low afterwards. Excluding routes across cities that met in the knock-out phase one year before avoids that mean reversion 12 months after the event results in downward bias of the $\beta$, because meeting in a knock-out phase in a year is correlated with the probability of ending in the same group the year after. Inclusion of these routes drives estimates downward and worsens precision, but is not crucial for any of the results shown. Importanlty, balance of treated and control routes holds also after excluding these routes.
} 
the last group phase game is played on the first week of December, and I exclude all routes across cities that played a knock-out phase match during the spring. Moreover, teams are not allowed to take part in more than one international competition a year, and once they compete in the Champions' League group phase they have no opportunity to meet until the next season (unless they advance in the Champions League and are pitched in a knock-out game, in which case they are dropped from my sample).

\section{The First Appearance of a Team}

Many teams play in the Champions' League every year. While repeated exposure may increase the visibility of their cities, the effect may have diminishing returns. I explore this possibility by examining the differential effect of taking part in the Champions' League for the first time. ${ }^{14}$ In all, 56 teams made their first appearance during the period of study: 13.5 percent of the 416 teams who took part in these editions. I estimate:

$$
\begin{aligned}
\log P_{i j, m}= & \alpha_{i j}+\delta_{t}+\beta^{N} \cdot G_{i j} \cdot N_{i j}+\beta^{V} \cdot G_{i j} \cdot V_{i j} \\
& +\chi N_{i j}+\Sigma \phi^{c}\left(c_{i}+c_{j}\right) \cdot t+\Sigma \psi^{c}\left(c_{i}-c_{j}\right) \cdot t+e_{i j, m}
\end{aligned}
$$

\footnotetext{
${ }^{14}$ I thank one referee for suggesting this exercise.
} 
Where $N_{i j}=1$ if the team of either city $i$ or city $j$ makes its first appearance in the Champions League and 0 otherwise. $V_{i j}=1$ if both teams are "veterans," that is: they already played in the Champions' League $\left(N_{i j}+V_{i j}=1\right.$ always $)$. The other variables are defined above.

Table 3 reports the results of the exercise. On average routes connecting cities that had one new team are less busy (the coefficient of $N_{i j}$ is mostly negative). However, the Champions' League group phase represents a bigger shock for these routes: on the month of the match traffic grows by 13.7 percent in these routes, compared to 5.7 percent for the other ( $p$-value of the difference $=0.106$ ). The effect is similar in January and February and becomes somewhat larger from March on, although none of these differences is significant.

These results suggest two conclusions. First, the match represents a greater shock to routes that take part to the competition for the first time. Second, media exposure affects new and repeatedly exposed routes in a similar way during January and February, when the Champions' League pauses. When the competition starts again however, there is suggestive evidence that routes across cities with new teams continue to benefit from the treatment, while routes across cities that were already in the competition before cease to enjoy greater traffic. Overall, the results provide suggestive evidence that the visibility effect of the competition has diminishing returns. 


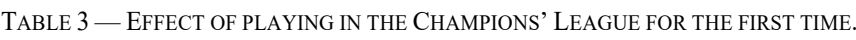

\begin{tabular}{|c|c|c|c|c|c|c|c|c|c|}
\hline & $\begin{array}{c}\beta \text { first } \\
\text { appearance }\end{array}$ & s.e. & $\begin{array}{l}\beta \text { other } \\
\text { appear. }\end{array}$ & s.e. & $\begin{array}{c}\text { First } \\
\text { appear. }\end{array}$ & s.e. & Obs. & $\begin{array}{l}\text { Route, Year FE } \\
\& \text { country trends }\end{array}$ & $\begin{array}{l}\text { Month FE } \\
\& \text { trends }\end{array}$ \\
\hline Month of match ${ }^{a}$ & $0.137 * * *$ & $(0.046)$ & $0.057^{* * *}$ & $(0.017)$ & -0.026 & $(0.027)$ & 6136 & Yes & Yes \\
\hline January & 0.076 & $(0.098)$ & $0.085^{* *}$ & $(0.037)$ & 0.044 & $(0.062)$ & 1344 & Yes & No \\
\hline February & 0.053 & $(0.082)$ & $0.066^{*}$ & $(0.035)$ & -0.015 & $(0.058)$ & 1346 & Yes & No \\
\hline $\operatorname{March}^{b}$ & 0.108 & $(0.080)$ & $0.057^{*}$ & $(0.032)$ & -0.068 & $(0.057)$ & 1340 & Yes & No \\
\hline April $^{\text {b }}$ & $0.144^{*}$ & $(0.079)$ & 0.031 & $(0.032)$ & -0.038 & $(0.059)$ & 1358 & Yes & No \\
\hline May $^{b}$ & 0.109 & $(0.089)$ & 0.033 & $(0.033)$ & -0.061 & $(0.058)$ & 1354 & Yes & No \\
\hline June & 0.117 & $(0.075)$ & 0.021 & $(0.025)$ & -0.049 & $(0.048)$ & 1584 & Yes & No \\
\hline July & 0.058 & $(0.074)$ & 0.015 & $(0.025)$ & -0.036 & $(0.053)$ & 1584 & Yes & No \\
\hline August & 0.102 & $(0.081)$ & 0.026 & $(0.025)$ & -0.068 & $(0.052)$ & 1584 & Yes & No \\
\hline
\end{tabular}

Notes: The table reports estimates of $\beta^{N}, \beta^{V}$ and $\chi$ in equation (4). The sample includes all routes across cities that had at least 1 team taking part in the Champions' League group phase during the current edition. I exclude all routes that: (i) could not have been treated given the seeding structure of the random draw; (ii) connect cities in Israel, Russia, Serbia, Turkey or Ukraine and (iii) had their teams met in the later stages of the competition either in the current or in the previous edition of the Champions League. The dependent variable $\left(\log P_{i j, m}\right)$ has the top and bottom 0.5 percent of observations winsorized. Standard errors in parentheses are clustered at the route-month-year level. See text for details.

Source: Author calculations.

${ }^{a}$ September through December. ${ }^{b}$ Knock-out phase.

*** Significant at the 1 percent level.

** Significant at the 5 percent level.

* Significant at the 10 percent level. 


\section{Robustness Checks}

In this section I demonstrate the robustness of my results.

\section{A. Time-Varying Unobservable Characteristics}

The estimates on Table 2 have a causal interpretation if, conditional on route fixed effects, there are no unobservable characteristics affecting both selection into treatment and outcome. These unobservables would need to be time-varying: fixed effects take care of time-invariant confounders (cf. Smith \& Todd 2005 critique to Dehejia \& Wahba 1999). Such unobservable characteristics are unlikely to pose a major threat to identification because of the random assignment of treatment. Balance of observable characteristics before treatment -including the changes in passengers- support this conclusion. In this section I propose an additional robustness test to assess the importance of time-varying unobservables.

In Table 4 I report estimates from an augmented equation (3), where I control for a polynomial in time specific to both cities in a route. I estimate variants of:

$$
\log P_{t j m}=\alpha_{t j}+\delta_{t}+\beta \cdot G_{t j}+f(t) \cdot t+g(t) \cdot f+e_{t j m}
$$

Where $f(t)$ and $g(t)$ are time polynomials specific to city $i$ and $j$. In Table 4-Panel A all regressions include linear trends. Panel B (Panel C) include a separate $2^{\text {nd }}$ $\left(3^{\text {rd }}\right)$ order polynomial in time for every city. These regressions allow to control for factors such as city growth which may correlate positively with both arrivals 
and the probability of treatment (through movement of a city's team across pots, say). The inclusion of these controls has little effect on point estimates and significance, confirming the validity of the identification strategy.

\section{B. Robust Inference}

In this section I demonstrate the robustness of my main results to alternative methods of inference. Until now, I use standard errors clustered at route-monthyear level. This corrects for the most important source of bias in the formula for robust standard errors: the perfect correlation of treatment within routes $\left(G_{i j, t}=\right.$ $G_{j i, t}$ always) combined with the positive correlation of errors on the two ways of a

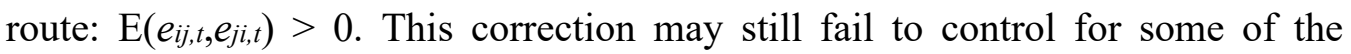
correlation across units, and in this section I present exercises that demonstrate the resulting potential bias is small and does invalidate any of my conclusions.

To understand the nature of the problem, consider the formula for clustered standard errors (adapted from equation (2) in Cameron and Miller, 2015):

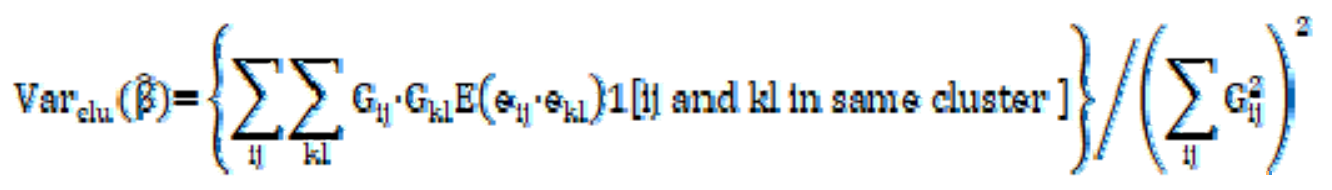

Where $1[\cdot]$ is an indicator variable for route $i j$ and route $k l$ being in the same cluster, sums are over all possible routes, time subscripts are omitted for simplicity and I consider two separate observations for each direction of the same route-month-year. 
TABLE 4 - Robustness to CitY-SPeCIFIC TIME TRENDS.

\begin{tabular}{|c|c|c|c|c|c|c|}
\hline \multicolumn{7}{|c|}{ PANEL A - City-specific linear trends } \\
\hline & $\beta$ & s.e. & Obs. & $\begin{array}{l}\text { Route } \\
\text { FE }\end{array}$ & $\begin{array}{l}\text { Year FE \& city } \\
\text { linear trends }\end{array}$ & $\begin{array}{l}\text { Month FE \& } \\
\text { month trends }\end{array}$ \\
\hline Month of the match ${ }^{\mathrm{a}}$ & $0.058 * * *$ & $(0.016)$ & 6136 & Yes & Yes & Yes \\
\hline January & $0.085^{* *}$ & $(0.035)$ & 1344 & Yes & Yes & No \\
\hline February & $0.063 * *$ & $(0.031)$ & 1346 & Yes & Yes & No \\
\hline March $^{\mathrm{b}}$ & $0.061 * *$ & $(0.028)$ & 1340 & Yes & Yes & No \\
\hline April $^{\mathrm{b}}$ & $0.048^{*}$ & $(0.029)$ & 1358 & Yes & Yes & No \\
\hline May ${ }^{b}$ & 0.040 & $(0.029)$ & 1354 & Yes & Yes & No \\
\hline June & 0.026 & $(0.022)$ & 1584 & Yes & Yes & No \\
\hline July & 0.013 & $(0.024)$ & 1584 & Yes & Yes & No \\
\hline August & 0.028 & $(0.023)$ & 1584 & Yes & Yes & No \\
\hline \multicolumn{7}{|c|}{ PANEL B - City-specific quadratic trends } \\
\hline & $\beta$ & s.e. & Obs. & $\begin{array}{l}\text { Route } \\
\text { FE }\end{array}$ & $\begin{array}{l}\text { Year FE \& city } \\
\text { quadratic trends }\end{array}$ & $\begin{array}{l}\text { Month FE \& } \\
\text { month trends }\end{array}$ \\
\hline Month of the match ${ }^{\mathrm{a}}$ & $0.055^{* * *}$ & $(0.015)$ & 6136 & Yes & Yes & Yes \\
\hline January & $0.080^{* *}$ & $(0.036)$ & 1344 & Yes & Yes & No \\
\hline February & $0.062 * *$ & $(0.032)$ & 1346 & Yes & Yes & No \\
\hline $\operatorname{March}^{\mathrm{b}}$ & $0.057^{* *}$ & $(0.027)$ & 1340 & Yes & Yes & No \\
\hline April $^{\text {b }}$ & 0.044 & $(0.028)$ & 1358 & Yes & Yes & No \\
\hline May ${ }^{b}$ & 0.030 & $(0.026)$ & 1354 & Yes & Yes & No \\
\hline June & 0.014 & $(0.021)$ & 1584 & Yes & Yes & No \\
\hline July & -0.009 & $(0.021)$ & 1584 & Yes & Yes & No \\
\hline August & 0.011 & $(0.020)$ & 1584 & Yes & Yes & No \\
\hline \multicolumn{7}{|c|}{ PANEL C-City-specific cubit trends } \\
\hline & $\beta$ & s.e. & Obs. & $\begin{array}{l}\text { Route } \\
\text { FE }\end{array}$ & $\begin{array}{l}\text { Year FE \& city } \\
\text { cubic trends }\end{array}$ & $\begin{array}{l}\text { Month FE \& } \\
\text { month trends }\end{array}$ \\
\hline Month of the match ${ }^{\mathrm{a}}$ & $0.059 * * *$ & $(0.015)$ & 6136 & Yes & Yes & Yes \\
\hline January & $0.069 * *$ & $(0.033)$ & 1344 & Yes & Yes & No \\
\hline February & $0.063 * *$ & $(0.031)$ & 1346 & Yes & Yes & No \\
\hline $\operatorname{March}^{\mathrm{b}}$ & $0.057^{* *}$ & $(0.028)$ & 1340 & Yes & Yes & No \\
\hline April $^{\mathrm{b}}$ & $0.047^{*}$ & $(0.028)$ & 1358 & Yes & Yes & No \\
\hline May $^{\mathrm{b}}$ & 0.023 & $(0.026)$ & 1354 & Yes & Yes & No \\
\hline June & 0.002 & $(0.021)$ & 1584 & Yes & Yes & No \\
\hline July & -0.019 & $(0.021)$ & 1584 & Yes & Yes & No \\
\hline August & -0.003 & $(0.020)$ & 1584 & Yes & Yes & No \\
\hline
\end{tabular}

Notes: The table reports estimates of $\beta$ in equation (4). The sample includes all routes across cities that had at least 1 team taking part in the Champions League group phase during the current edition. I exclude all routes that: (i) could not have been treated given the seeding structure of the random draw; (ii) connect cities in Israel, Russia, Serbia, Turkey or Ukraine and (iii) had their teams met in the later stages of the competition in the current or previous edition of the Champions League. Regressions in Panel A control for city-specific linear trends. Regressions in Panel B control for city-specific quadratic trends. Regressions in Panel C control for cityspecific cubic trends. The dependent variable has the top and bottom 0.5 percent of observations winsorized. Standard errors in parentheses are clustered at the route-month-year level.

${ }^{a}$ September through December. ${ }^{b}$ Knock-out phase.

$* * *$ Significant at the 1 percent level.

** Significant at the 5 percent level.

* Significant at the 10 percent level. 
Given the (unknown) true definition of clusters, the bias of incorrect clustering depends on the characteristics of clusters excluded from the calculation. In other words, given the correct set of indicators $1[\cdot]$, the bias of incorrect clustering is a function of the relationship between observations for which $1[\cdot]$ was erroneously set to 0 . Three factors determine the bias of the standard errors: (1) the correlation of treatment across these units, (2) the correlation of errors across these units and (3) the size of the excluded clusters: that is, the number of indicator variables erroneously set to 0 .

In what follows, I compare baseline standard errors to three alternative definitions of clusters: the first considers potential bias coming from the first factor and the other two from the second factor. Baseline standard errors are clustered at route-month-year level. This assumes that only routes connecting the same cities in the same month-year belong in the same clusters. In the present setting this correction is important because both $G_{i j, t}$ and $e_{i j, t}$ are likely to be correlated within these clusters. The second column of Table 5 reproduces these standard errors for reference.

Next, I consider potential bias coming from the correlation of treatment across routes: $G_{i j, t .}$ Column 3 of Table 5 shows standard errors clustered at the groupyear level. This takes into account that routes across cities in the same group have correlated $G_{i j, t}$ (for any three cities $i, j$ and $k$ with a team in the same group $G_{i j, t}=$ 
$\left.G_{i k, t}=G_{j k, t}\right)$. The correction has small effect on standard errors and negligible on significance, possibly because errors across these units have low correlation.

The second and third corrections account for possible correlation of errors $e_{i j, t .}$ Column 4 of Table 5 shows standard errors clustered at route level. This allows errors on a given route to be correlated on the two direction of the route and overtime. The correction has a modest effect on size of standard errors and significance, possibly because even though errors are serially correlated, the treatment is not. ${ }^{15}$

Column 5 of Table 5 presents dyadic standard errors (Fafchamps and Guber 2007a and 2007b). The correction allows errors across any two routes to be correlated whenever they share at least one city. In other words, $1[i j$ and $k l$ in same cluster $]=1$ whenever $i=k$ or $i=l$ or $j=k$ or $j=l$. This effectively accounts for correlation coming from city-level shocks (as opposed to route-level shocks). These standard errors are if anything larger than the baseline, suggesting that citylevel shocks do not invalidate inference, possibly because the treatment is assigned to every city in the sample.

\footnotetext{
15 The coefficient of a regression of treatment status on its lag on yearly data gives a coefficient of $0.01, p$-value $=0.75$.
} 
TABLE 5 - ROBUSTNESS FOR THE EFFECT OF PLAYING IN THE SAME GROUP OF THE CHAMPIONS LEAGUE.

\begin{tabular}{|c|c|c|c|c|c|c|c|c|}
\hline \multicolumn{9}{|c|}{ Standard errors } \\
\hline & $\beta$ & $\begin{array}{l}\text { Clustered: } \\
\text { route-year }\end{array}$ & $\begin{array}{l}\text { Clustered: } \\
\text { group-year }\end{array}$ & $\begin{array}{l}\text { Clustered: } \\
\text { route }\end{array}$ & Dyadic & Obs. & $\begin{array}{c}\text { Route \& } \\
\text { Year FE \& } \\
\text { country } \\
\text { trends }\end{array}$ & $\begin{array}{c}\text { Month FE } \\
\& \text { month } \\
\text { trends }\end{array}$ \\
\hline $\begin{array}{l}\text { Month of the } \\
\text { match }^{\mathrm{a}}\end{array}$ & 0.067 & $(0.016)^{* * *}$ & $(0.020)^{* * *}$ & $(0.016)^{* * *}$ & $(0.016)^{* * *}$ & 6136 & Yes & Yes \\
\hline January & 0.084 & $(0.035)^{* *}$ & $(0.039)^{* *}$ & $(0.039)^{* *}$ & $(0.031)^{* * *}$ & 1344 & Yes & No \\
\hline February & 0.064 & $(0.032)^{* *}$ & $(0.030)^{* *}$ & $(0.037)^{*}$ & $(0.029)^{* *}$ & 1346 & Yes & No \\
\hline $\operatorname{March}^{\mathrm{b}}$ & 0.062 & $(0.028)^{* *}$ & $(0.030)^{* *}$ & $(0.031)^{* *}$ & $(0.025)^{* *}$ & 1340 & Yes & No \\
\hline April $^{\mathrm{b}}$ & 0.045 & $(0.030)$ & $(0.035)$ & $(0.030)$ & $(0.031)$ & 1358 & Yes & No \\
\hline May ${ }^{b}$ & 0.042 & $(0.030)$ & $(0.038)$ & $(0.030)$ & $(0.030)$ & 1354 & Yes & No \\
\hline June & 0.030 & $(0.023)$ & $(0.025)$ & $(0.024)$ & $(0.022)$ & 1584 & Yes & No \\
\hline July & 0.033 & $(0.024)$ & $(0.027)$ & $(0.025)$ & $(0.023)$ & 1584 & Yes & No \\
\hline August & 0.019 & $(0.025)$ & $(0.027)$ & $(0.026)$ & $(0.024)$ & 1584 & Yes & No \\
\hline
\end{tabular}

Notes: The table reports estimates of $\beta$ in equation (3). The sample includes all routes across cities that had at least 1 team taking part in the Champions League group phase during the current edition. I exclude all routes that: (i) could not have been treated given the seeding structure of the random draw; (ii) connect cities in Israel, Russia, Serbia, Turkey or Ukraine and (iii) had their teams met in the later stages of the competition either in the current or in the previous edition of the Champions League. The dependent variable has the top and bottom 0.5 percent of observations winsorized. See text for details.

Source: Author calculations.

${ }^{a}$ September through December. ${ }^{b}$ Knock-out phase.

*** Significant at the 1 percent level.

** Significant at the 5 percent level.

* Significant at the 10 percent level.

Until now, all inference relies on asymptotically correct covariance matrices. In one last exercise I follow Young (2019) and exploit the known structure of the Champions' League random draw to perform randomized inference. This approach has the advantage to produce exact tests irrespective of sample size and errors covariances. In this exercise, I take the set of all routes across cities that had at least one team playing in the Champions' League group phase between 1998 and 2010, and randomly create groups of four teams following the same rules UEFA applies to create its groups. Every year, each one of my groups is made of exactly one team randomly drawn from each of the four pots. I also make 
sure that no two teams from the same football federation ever end up in the same group.

TABle 6 - RESUltS FROM 1000 PlaceBo Simulations OF THE TREATMENT.

\begin{tabular}{|c|c|c|c|c|}
\hline & $\begin{array}{c}\text { Simulations with } \\
\text { p-value smaller than } 0.05\end{array}$ & $\begin{array}{l}95^{\text {th }} \text { percentile of } \\
\text { estimates in simulations }\end{array}$ & True $\beta$ & $\begin{array}{c}\text { Simulations larger } \\
\text { than true } \beta^{\text {a }}\end{array}$ \\
\hline & (1) & (2) & (3) & (4) \\
\hline Month of the match ${ }^{b}$ & $8.6 \%$ & 0.038 & 0.067 & $0.1 \%$ \\
\hline January & $5.2 \%$ & 0.068 & 0.084 & $1.5 \%$ \\
\hline February & $6.2 \%$ & 0.067 & 0.064 & $5.7 \%$ \\
\hline $\operatorname{March}^{\mathrm{c}}$ & $6.3 \%$ & 0.061 & 0.062 & $4.6 \%$ \\
\hline April $^{\mathrm{c}}$ & $6.2 \%$ & 0.051 & 0.045 & $6.9 \%$ \\
\hline May $^{\mathrm{c}}$ & $5.5 \%$ & 0.048 & 0.042 & $8.4 \%$ \\
\hline June & $4.9 \%$ & 0.039 & 0.030 & $10.3 \%$ \\
\hline July & $4.1 \%$ & 0.037 & 0.033 & $6.7 \%$ \\
\hline August & $4.4 \%$ & 0.039 & 0.019 & $22.5 \%$ \\
\hline
\end{tabular}

Notes: Column (1) reports the percentage of simulations in which the effect of a placebo treatment was estimated to be different from 0 at the 5 percent confidence level. Placebo treatments are defined according to the same rules used to form the Champions League groups. I run 1000 simulations: every time I estimate equation (3) substituting the true treatment $G_{i j}$ with this placebo treatment. Column (2) reports the $95^{\text {th }}$ percentile of the simulated $\beta$. Column (3) reports the true $\beta$ from table 2 . Column (4) reports the percentage of simulations with an estimated $\beta$ larger than the one reported in column 2.

Source: Author calculations.

${ }^{a}$ From table 2. ${ }^{\mathrm{b}}$ September through December. ${ }^{\mathrm{c}}$ Knock-out phase.

I draw 1000 such placebo treatments and for each draw I estimate regression (3) with standard errors clustered at route-year level and store the $p$-value of the coefficient $\beta$. The first column of Table 6 shows for each months in which 
regression (3) is estimated, the percentage of simulations that had a $p$-value smaller than 0.05 . The results suggest that with route-year clustering the error structure biases standard errors slightly downward. However, the last column in Table 6 also suggests that estimated treatment effects remain significant even with randomized inference: if anything, the effect in later months approaches conventional levels of significance. One reason why results from exact tests from randomized inference may be similar to tests based on asymptotic distributions is because the number of clusters used for calculation is large. ${ }^{16}$

Taken together, the exercises in this section confirm the robustness of the results to alternative methods of inference.

\section{Summary}

Do professional teams make their hometowns more visible among tourists? Using a natural experiment embedded in the European Champions' League competition, I show that cities hosting teams receive more visitors from cities where Champions League games are more salient. My findings provide the first causal evidence that teams have the potential to increase the visibility of their hometowns. To the extent that my results carry over to the US, they may help explain Carlino and Coulson's (2004) finding that house rents are significantly

\footnotetext{
${ }^{16}$ In the regressions in January, with route-level clustering there are 287 clusters; with group-year clustering 425 and with route-month-year clustering 672 .
} 
higher in U.S. cities with NFL franchises. The greater visibility of these cities may increase the flow of visitors, which would bring direct advantages for retail business and hotels for example, and ultimately should increase rents.

In any case, it is important to stress that the visibility effect I find appears to have diminishing returns and require continuous media exposure. The first appearance of a team on the competition represents a larger shock to air travel than subsequent participations, suggesting diminishing returns. Moreover, the effect of playing in the same group of the Champions League disappears soon after teams stop playing against each other. This implies that the visibility effects depend on the structure of the competitions. For example, teams that play more games per season may be more valuable for the visibility of a city. 


\section{Appendix A. Data description}

I source air traffic data from Eurostat's "Detailed air passenger transport by reporting country and routes" tables ${ }^{17}$. For every airport in each European country, this database contains information on monthly air travel on every route from 1998 to 2010 . On every route both arrivals and departures are available. Moreover, two different variables are available both for arrivals and for departures: total number of passengers carried and total number of passengers onboard. Passengers onboard equals passengers carried plus passengers that stop over and proceed to a different destination on the same aircraft, but in practice the two measures are almost identical (between January and August the correlation is $0.9994, p$-value $<0.0001)$. Since for some countries only one between passengers carried and passengers onboard is reported, I pool all available information as follows. There are 4 measures of number of arrivals on each direction of a route: passengers carried and passengers onboard recorded as arrivals in the airport of destination, and passengers carried and passengers onboard recorded as departure in the airport of origin. The dependent variable used in the paper is the simple average of all measures available on every direction of a route. In the regressions shown in table 2, 67.9 percent of routes have all 4 measures available between January and August. Using information from the other end of a route cleans some

\footnotetext{
${ }^{17}$ Data are available online at: http://epp.eurostat.ec.europa.eu/portal/page/portal/transport/data/database.
} 
of the noise present at the end of every month, when some passengers are recorded as flying on one month in one airport and on the following one at the other end ${ }^{18}$. In all regressions I use the natural logarithm of the dependent variable so defined, and I winsorize the top and bottom 0.005 percent of observations to avoid extreme values to drive results.

Both tourism data (night spent in every NUTS 2 region) and demographic and economic data for European cities come from Eurostat ${ }^{19}$. Data on rail, maritime and road travel across and within European countries also come from Eurostat, and refer only to the countries used in the regressions ${ }^{20}$. Data on geographic coordinates of every European city used to compute distances come from Wikipedia. I hand-collected every match of the UEFA Champions League from the $1997-98$ to the $2010-11$ edition from the UEFA official website ${ }^{21}$.

\section{Appendix B. Dyadic Regression}

This appendix is based on Fafchamps and Gubert (2007a and 2007b): refer to these papers for details. Both air traffic $\left(\log P_{i j, m}\right)$ and the Champions League treatment $\left(G_{i j}\right)$ are observed on networks in which observations are city-pairs, and

\footnotetext{
18 Although also arrivals from $j$ to $i$ are very correlated with departures from $j$ to $i(0.9942, p$-value $<0.0001)$ every month during which the former are greater than the latter are followed by a month in which the opposite happens, by exactly the same number of passengers.

19 Tourism data is available at http://epp.eurostat.ec.europa.eu/portal/page/portal/tourism/data/database; data on cities at http://epp.eurostat.ec.europa.eu/portal/page/portal/region_cities/city_urban/data_cities/database_sub1.

20 All available at: http://epp.eurostat.ec.europa.eu/portal/page/portal/transport/data/database.

21 Online at: http://www.uefa.com/uefachampionsleague/history/.
} 
every city appears on several different pairs. Regression analysis on network data requires to specify a dyadic model, and both identification and inference need to be adjusted: I discuss these issues in turn.

Identification.-A simpler version of the dyadic regression analyzed in the text takes the form:

$$
\log P_{i j}=\alpha+\beta \cdot G_{i j}+\varepsilon_{i j}
$$

where time subscripts are omitted for simplicity. In (B1) the treatment $G_{i j}$ is specific to the route across city $i$ and city $j$ : in this case identification does not require any correction. When characteristics specific to the two cities enter a dyadic regression however, it is important that they affect both ways of the route symmetrically: this means that the effect of city characteristic $c$ on air travel must be such that the effect of $c_{i}$ and $c_{j}$ on $\log P_{i j}$ is the same as the effect of $c_{j}$ and $c_{i}$ on $\log P_{j i}$. In order to impose this symmetry, Fafchamps and Gubert (2007a and 2007b) propose two different solutions, depending on whether the dyadic relationship is directional (as with air traffic, for which $\log P_{i j} \neq \log P_{j i}$ ) or undirectional (as the average arrivals across a route $\log A v g P_{i j}=\log A v g P_{j i}$ ). When the relationship is directional, symmetry is imposed by specifying the model:

$$
\log P_{i j}=\alpha+\beta \cdot G_{i j}+\varphi\left(c_{i}+c_{j}\right)+\psi\left(c_{t}-c_{j}\right)+\varepsilon_{i j}
$$


When the dyadic relationship is un-directional, symmetry is satisfied with:

$$
\log A v g P_{i j}=\alpha+\beta \cdot G_{i j}+\varphi\left(c_{i}+c_{j}\right)+\psi\left|c_{i}-c_{j}\right|+\varepsilon_{i j},
$$

Regressions (2) and (3) are directional dyadic regressions (since arrivals from $j$ to $i$ in month $m$ need not be equal to arrivals from $i$ to $j$ during the same period): in these regressions country-trends must enter the equation as in (B2). The dependent variables in the regressions on data collapsed at the route-month level and the treatment $G_{i j}$ define $u n$-directional relationships $\left(\log A v g P_{i j}=\log A v g P_{j i}\right.$ and $G_{i j}=G_{j i}$. For this reason country dummies enter regressions on collapsed data as in (B3), and for every city-specific variable for which I test the equality of means in table $1 \mathrm{I}$ do so both for the sum and for the absolute difference across the two cities on a route.

Inference.- Standard errors in model (B1) need to take into account that shocks affecting city $i$ will have an impact on all routes connecting $i$, and that this is true for all cities on all routes. This implies that in general $\mathrm{E}\left(e_{i j}, e_{k l}\right) \neq 0$ whenever $i=k$ or $i=l$ or $j=k$ or $j=l$, and that the structure of the errors in regression (B1) has a form similar to that of a regression with clusters. Fafchamps and Gubert (2007a and $2007 \mathrm{~b}$ ) propose to correct the variance-covariance matrix of coefficients in a dyadic regression with a formula similar to the one proposed by Conley (1999) for spatially correlated errors: 


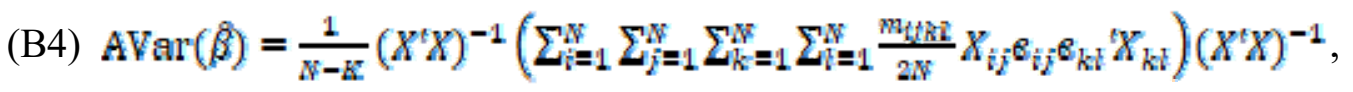
where $\hat{\beta}$ is the $K \times 1$ vector of estimated coefficient, $N$ is the number of observations $X$ is the matrix of all regressors, $e_{i j}$ is the error in equation (B1) and $m_{i j k l}=1$ if either $i=k$ or $i=l$ or $j=k$ or $j=l$.

Fafchamps and Gubert (2007a and 2007b) estimate (B4) on complete networks, i.e. networks in which every node is connected to every other node in the network. However, the air traffic network analyzed here is not complete: first, not every city has a direct connection to every other city taking part in the Champions League (there might exist both a Rome-Lille and a Rome-Valencia route, but no Lille-Valencia connection). Second, even if all routes existed, some routes are not valid "controls" for my treated routes, because cities that had teams in the same pot could not meet, and teams from the same country can not end up in the same group. In order to estimate (B4) on an incomplete network I coded a new option in the Stata program provided by Fafchamps: this is available on my website. ${ }^{22}$

\footnotetext{
22 Here: https://drive.google.com/uc?export=download\&id=0B2ZiMgcf6J3wR2hqSzQwXzk4YTg.
} 


\section{Appendix C. The UEFA Champions League}

The first edition of the UEFA Champions League was held in 1955-56. Since then the number of participating teams and the general format of the competition have both changed many times. The group phase was introduced in the 1991-92 edition, and since 1994-95 all the matches in the group phase have been played between September and the first week of December. The number of groups has grown overtime, but these have always been formed randomly. Since the 19992000 edition there have always been 8 groups.

The rules to admit teams to the group phase vary by country and by year. "Major" leagues send the first 2 or 3 teams of the previous season directly to the group stage. Teams that ended first and second in one of the "minor" leagues, and teams that ended third or fourth in one of the major leagues take part to a "preliminary phase". Official country rankings determine the number of teams that every country can send to the group phase or to the preliminary phase. These rankings are updated by UEFA every season according to 5-year moving average of the performance of national teams in all European competitions. The preliminary phase, played between July and August, consist of a series of knockout matches that selects 10 of the 32 teams participating in the group phase. These games are not very popular and, since UEFA does not manage directly the TV 
rights for these games, they are only occasionally broadcasted, even in interested countries (European Commission, 2003).

Note that the format of the competition implies that both the year and the countries of team pairs might be correlated with the treatment. Year matters because the rules to qualify changed overtime (most notably in 1999, when the number of participating teams became 32 , and in 2009 , when the rules to access the group phase were renewed). These changes might have affected the probability of any 2 particular teams to meet, even conditional on reaching the group stage. Country specific trends are important because the number of participating teams from any country, and the pots where these teams are seeded depend on national UEFA coefficients, which in turn are updated every year, according to the current and past performance of national teams in UEFA competitions. Country rankings have evolved very differently over the last decade, often trailing domestic economic growth. For this reason, they might correlate with both the probability of treatment and the evolution of air traffic. In order to control for this confounders I include in every specification a set of dummies for both years and country of origin of the two teams. 


\section{REFERENCES}

Baade, Robert A. 1996. "Professional Sports As Catalysts For Metropolitan Economic Development." Journal of Urban Affairs, 18(1): 1-17.

Baumann, Robert W., Victor A. Matheson, and Chihiro Muroi. 2009 "Bowling in Hawaii: Examining the effectiveness of sports-based tourism strategies." Journal of Sports Economics 10(1): 107-123.

Baumann, Robert W., and Victor A. Matheson. 2017. "Many happy returns? The Pro-Bowl, mega-events, and tourism in Hawaii." Tourism Economics 23(4):788-802.

Baumann, Robert, and Victor Matheson. 2018. "Mega-Events and Tourism: The Case of Brazil.” Contemporary Economic Policy 36(2): 292-301.

Bruhn, Miriam, and David McKenzie. 2009 "In Pursuit of Balance: Randomization in Practice in Development Field Experiments." American Economic Journal: Applied Economics, 1(4): 200-232.

Cameron, A. Colin, and Douglas L. Miller. 2015. "A practitioner's guide to cluster-robust inference." Journal of Human Resources 50(2): 317-372.

Carlino, Gerald, and Edward N. Coulson. 2004. "Compensating Differentials and the Social Benefits of the NFL." Journal of Urban Economics, 56(1): 2550.

Chikish, Yulia, Brad R. Humphreys, Crocker Liu and Adam Nowak. 2019. 
"Sports-Led Tourism, Spatial Displacement, and Hotel Demand." Economic Inquiry 57(4): 1859-1878.

Coates, Dennis. 2007. "Stadiums And Arenas: Economic Development Or Economic Redistribution?," Contemporary Economic Policy, 25(4): 565-577.

Coates, Dennis, and Brad R. Humphreys. 2003 “The effect of professional sports on earnings and employment in the services and retail sectors in US cities," Regional Science and Urban Economics, 33(2): 175-198.

Coates, Dennis, and Brad R. Humphreys. 2006. "Proximity benefits and voting on stadium and arena subsidies.” Journal of Urban Economics, 59(2): 285-299.

Coates, Dennis, Brad R. Humphreys, and Andrew Zimbalist. 2006. "Compensating differentials and the social benefits of the NFL: A comment." Journal of Urban Economics 60(1): 124-131.

Conley, Timothy G. 1999. "GMM estimation with cross sectional dependence," Journal of Econometrics, 92(1): 1-45.

Dehejia, Rajeev H., and Sadek Wahba. 1999. "Causal effects in nonexperimental studies: Reevaluating the evaluation of training programs." Journal of the American statistical Association 94(448): 1053-1062.

Depken, Craig A., and E. Frank Stephenson. 2018. "Hotel demand before, during, and after sports events: evidence from Charlotte, North Carolina." Economic Inquiry 56(3): 1764-1776.

European Commission. 2003. "Commission Decision of 23 July 2003 relating to 
a proceeding pursuant to Article 81 of the EC Treaty and Article 53 of the EEA Agreement." 2003/778/EC. (COMP/C.2-37.398 - Joint selling of the commercial rights of the UEFA Champions League).

Eurostat. 1990-2011. "Occupancy in collective accommodation establishments: domestic and inbound tourism. Nights spent in tourist accommodation establishments by NUTS 2 regions - annual data." European Commission, $\begin{array}{lll}\text { Eurostat, } & \text { Tourism } & \text { statistics. }\end{array}$ http://epp.eurostat.ec.europa.eu/portal/page/portal/tourism/data/database (accessed February 25, 2013).

Eurostat. 1998-2010. "Air transport measurement - passengers. Detailed air passenger transport by reporting country and routes." European Commission, $\begin{array}{lll}\text { Eurostat, } & \text { Transport }\end{array}$ http://epp.eurostat.ec.europa.eu/portal/page/portal/transport/data/database (accessed February 25, 2013).

Eurostat. 1999-2012. "Urban audit. Reduced set of derived indicators for 570 cities." European Commission, Eurostat, General and regional statistics. http://epp.eurostat.ec.europa.eu/portal/page/portal/region_cities/city_urban/data _cities/database_sub1 (accessed February 25, 2013).

Fafchamps, Marcel, and Flore Gubert. 2007a. "Risk Sharing and Network Formation," American Economic Review Papers \& Proceedings, 97(2): 75-79.

Fafchamps, Marcel and Flore Gubert. 2007b. "The formation of risk sharing 
networks," Journal of Development Economics, 83(2): 326-350.

Falk, Martin Thomas, and Markku Vieru. 2020. "Short-term hotel room price effects of sporting events.” Tourism Economics, 1354816620901953.

Fourie, Johan, and María Santana-Gallego. 2011. "The Impact of Mega-Sport Events on Tourist Arrivals." Tourism Management 32(6): 1364-1370.

Islam, Muhammad Q. 2019. "Local Development Effect of Sports Facilities and Sports Teams: Case Studies Using Synthetic Control Method." Journal of Sports Economics 20(2): 242-260.

Kim, Song-Hee, and Ward Whitt. 2015. "The power of alternative Kolmogorov-Smirnov tests based on transformations of the data." $A C M$ Transactions on Modeling and Computer Simulation (TOMACS) 25(4): 1-22.

Lavoie, Marc, and Gabriel Rodriguez. 2005 "The economic impact of professional teams on monthly hotel occupancy rates of Canadian cities: A Box-Jenkins approach.” Journal of Sports Economics 6(3): 314-324.

Propheter, Geoffrey. 2019. "Estimating the effect of sports facilities on local area commercial rents: Evidence from Brooklyn's Barclays Center." Journal of Sports Economics 20(1): 91-114.

Rose, Andrew K., and Mark M. Spiegel. 2011. "The Olympic Effect." Economic Journal 121(553): 652-677.

Rudkin, Simon, and Abhijit Sharma. 2019. "Live football and tourism expenditure: match attendance effects in the UK." European Sport Management 
Quarterly: 1-24.

Salgado-Barandela, Jesyca, Ángel Barajas, and Patricio Sánchez-Fernández. 2019. "Sport-event portfolios: An analysis of their ability to attract revenue from tourism." Tourism Economics: 1354816619884448.

Smith, Jeffrey A., and Petra E. Todd. 2005. "Does matching overcome LaLonde's critique of nonexperimental estimators?" Journal of Econometrics 125(1-2): 305-353.

Siegfried, John, and Andrew Zimbalist. 2000. "The Economics of Sports Facilities and Their Communities." Journal of Economic Perspectives, 14(3): $95-11$.

Young, Alwyn. 2019. "Channeling fisher: Randomization tests and the statistical insignificance of seemingly significant experimental results." Quarterly Journal of Economics 134(2): 557-598. 